\title{
Critical success factors of collaborative approach in delivering sustainable construction
}

\author{
Shia Hui Liu', Yani Rahmawati, ${ }^{1, *}$, and Noor Amila Wan Abdullah Zawawi² \\ ${ }^{1}$ Civil and Environmental Engineering Department, Faculty of Engineering, Universiti Teknologi PETRONAS, Seri Iskandar, Malaysia \\ ${ }^{2}$ Institute of Self-Sustainable Building, Universiti Teknologi PETRONAS, Seri Iskandar, Malaysia
}

\begin{abstract}
The essential aspect of sustainability in construction lead the complexities and involvement of multi parties in the construction project as well as its process. Conflicts of interests may appear in the process. Collaborative approach is essential for supporting decision making in delivering sustainable construction. This research identifies the collaboration critical factors. Scatter plot of mean and standard deviation analysis is done to rank the criticality of each collaboration factors in delivering sustainable construction. Eventually, factor analysis is done to identify the similarities between all the factors. There are twelve (12) factors identified from previous studies. Among all the collaboration factors, coordination among project stakeholders is identified as the most critical in delivering sustainable construction and followed by sharing responsibilities and mutual support. Based from factor analysis, five new factors of collaborative approach have been found.
\end{abstract}

\section{Introduction}

There are three key areas involved in sustainability. They are environmental responsibility; social awareness; and economic profitability. Achieving the right balance between these three key areas supports true sustainability. Given that there are a massive number of ongoing construction projects every year, the cumulative environmental impact from the projects becomes a serious problem that can cause significant damage, not only to ecosystems but also to the health and well-being of field workers and nearby residents of those projects [1]. Therefore, the construction industry has now emphasized in adopting the concept of sustainability to better protect the environment; being more profitable and competitive; as well as delivering buildings and structures that provide greater satisfaction, well-being and value to customers and users. Thus, sustainable construction is a trend nowadays and not only refers to the buildings and spaces but also the processes or activities used to construct the structures. Most of the structures and infrastructures are constructed under project-based setting. A construction project, especially those with sustainable construction intention, involves multi-disciplinary entities. Multi entities are needed in performing sustainable construction. The term entities in construction can refer to individuals, teams, units, departments, functional areas or organizations [2]. The entities can be categorised into three main roles which are owner/ developer; designer (architects and engineers); and contractor (main contractor, sub-contractor and specialist). Traditional

\footnotetext{
* Corresponding author: yani.rahmawati@utp.edu.my
}

construction project practice has been based on rigid and impermeable boundaries that have made communication, cooperation and integration a major challenge [3]. Hence, collaborative approach is essential in breaking the boundaries between entities involved in a construction project and finally delivering a successful sustainable construction. Research has suggested that successful collaboration allowing potential for learning and innovations; leading to project success as well as creating future collaboration opportunity [4]. Fig 1 [5] illustrates the collaborative decision model in construction, whereby in supporting the involvement of multi disciplines participants collaboration is essential. This research aims to seek critical success factors of collaborative approach in supporting decision making to deliver sustainable construction.

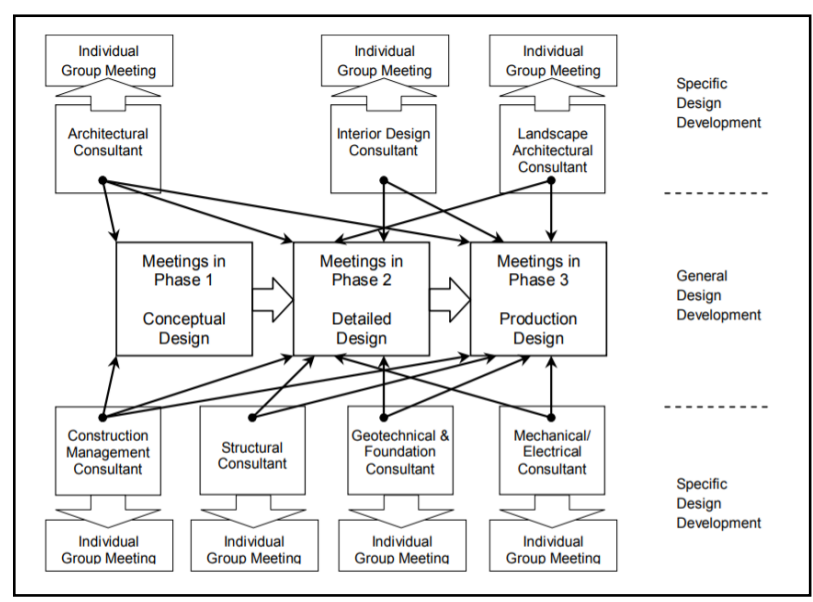

Fig. 1. Decision making model in construction [5] 


\section{Theoretical background}

Sustainability has been broadly discussed amongst previous studies, but that are not much research discussing the collaboration matters in delivering the sustainability. Review to previous related studies/ researches have been conducted to identify the critical factors and research position. The results are presented in Table 1 and also Fig. 2.

Factors which are physical, technical, and social factors as three main aspects to be considered in supporting successful collaboration at the planning stage of a project [6]. In term of physical aspect, ICT-based workspace is suggested to support virtual meeting in collaborative design. Applying Knowledge Management (KM) to support integration through shared understanding environment is the collaboration success factor in technical aspect. Considering social factors related with individual and team is another collaboration success factor in social aspect [6].

Providing knowledge related with organizational development in the project-based construction industry by identifying boundary actions in contemporary collaborative construction practices [3]. Empirical insights are given into three examples of boundary actions of a collaborative construction project: stakeholder boundary action, professional boundary action and geographical boundary action. From a project-as-practice perspective, these boundary actions turn out to be interesting renewal initiatives, providing increased understanding of where and how renewal can take place.

Adoption of target costing promises benefits for the construction industry as it struggles to raise the number of successful outcomes and certainty of project delivery in terms of cost, quality and time [7]. Target cost contracts specify a best estimate of the cost of the work to be carried out. During the course of the work, the initial target cost will be adjusted by agreement between the client or his nominated representative and the contractor to allow for any changes to the original specification. Difference between target cost and actual cost at completion are shared between the parties to the contract. A pain/gain share mechanism is the distinguishing feature of these contracts.

Dietrich et al. [4] have presented a conceptual framework that explains the focal collaboration related elements and their interdependencies in multi-partner projects. The conceptual framework explains how two collaboration mediators, project-collaboration quality and knowledge-integration capability, relate collaboration antecedents with collaboration outcomes. Knowledge integration refers to the ability of a project organization to turn knowledge into action. The concept of projectcollaboration quality is based on the following five elements through which the quality of collaboration is assessed: communication, coordination, mutual support, aligned efforts, and cohesion.

Garcia et al. [5] have developed a 'tripod' method of design that uses Virtual Design and Construction modelling (multi-disciplinary performance-based virtual design and construction modelling), an integrated POP model (a formal and integrated model of Product, Organization and Process of the project) and Extreme Collaboration (very rapid concurrent and technologically enabled social process of design). Under Virtual Design and Construction (VDC), the shared visualizations of the $\mathrm{P}, \mathrm{O}$ and $\mathrm{P}$ models allow all designers to see the impact of their design choices on their own and on related disciplines, as well as to give the opportunity for all designers to review the design choices of other disciplines. Extreme Collaboration (XC) is a working environment in which collocated experts work simultaneously in design 'sessions' while using excellent modelling, simulation, visualization and analysis tools to document and facilitate collaboration.

A Web-based system uses a centralized information integration approach through a shared Web server or a central database behind the Web server supports collaboration. Software agents are usually used to facilitate collaboration or interoperation among software systems, but they can also be applied to facilitate communication and collaboration among software system users, organizations, and hardware systems [8].

Bresnen \& Marshall [9] have set out to add to the growing literature and empirical database on partnering, by reporting the findings of a research project designed to explore the economic, organisational and technological factors that encourage or inhibit collaboration in practice. In construction, considerable steps had been taken towards eliminating role duplication and levels of specialisation were correspondingly reduced, with an emphasis placed upon flexibility in roles at site level. The projects let under partnering/alliancing arrangements included some form of incentive system, commonly based upon an agreed target cost with risk/reward element. Joint project offices were used to co-locate teams; the effects were universally regarded as beneficial, due to direct effects on communications and indirect effects in reinforcing collaborative behaviour.

Table 1. Factors of collaboative appoach in delivering sustainability

\begin{tabular}{|c|l|c|c|c|c|c|c|c|}
\hline NO & \multicolumn{3}{|c|}{ Collaborative Support Factors } & \multicolumn{3}{|c|}{ Previous Study } \\
\hline & & {$[7]$} & {$[3]$} & {$[8]$} & {$[4]$} & {$[10]$} & {$[11]$} & {$[9]$} \\
\hline I & Sharing stakeholders' operational responsibilities & & $\checkmark$ & & & & & $\checkmark$ \\
\hline II & Partnering/alliancing arrangements among project stakeholders & & & $\checkmark$ & & & & $\checkmark$ \\
\hline III & Smaller focus groups from all project stakeholders & $\checkmark$ & $\checkmark$ & & & & & \\
\hline IV & The use of compatible software & $\checkmark$ & & & & & $\checkmark$ & \\
\hline V & The use of knowledge management (KM) & $\checkmark$ & & & $\checkmark$ & & & \\
\hline
\end{tabular}




\begin{tabular}{|c|l|c|c|c|c|c|c|c|}
\hline NO & \multicolumn{1}{|c|}{ Collaborative Support Factors } & \multicolumn{3}{|c|}{ Previous Study } \\
\hline VI & Sharing workplace for all project stakeholders & {$[7]$} & {$[3]$} & {$[8]$} & {$[4]$} & {$[10]$} & {$[11]$} & {$[9]$} \\
\hline VII & Virtual workspace among all project stakeholders & & $\checkmark$ & & & & & $\checkmark$ \\
\hline VIII & Effective communication between all project stakeholders & $\checkmark$ & & & & & & \\
\hline IX & Coordination among project stakeholders & $\checkmark$ & & & $\checkmark$ & & & \\
\hline X & Mutual support between project stakeholders & & & & $\checkmark$ & & & \\
\hline XI & Alignment between expectations with the realisation of efforts & & & & $\checkmark$ & & & \\
\hline XII & Cohesion among project stakeholders & & & & $\checkmark$ & & & \\
\hline
\end{tabular}

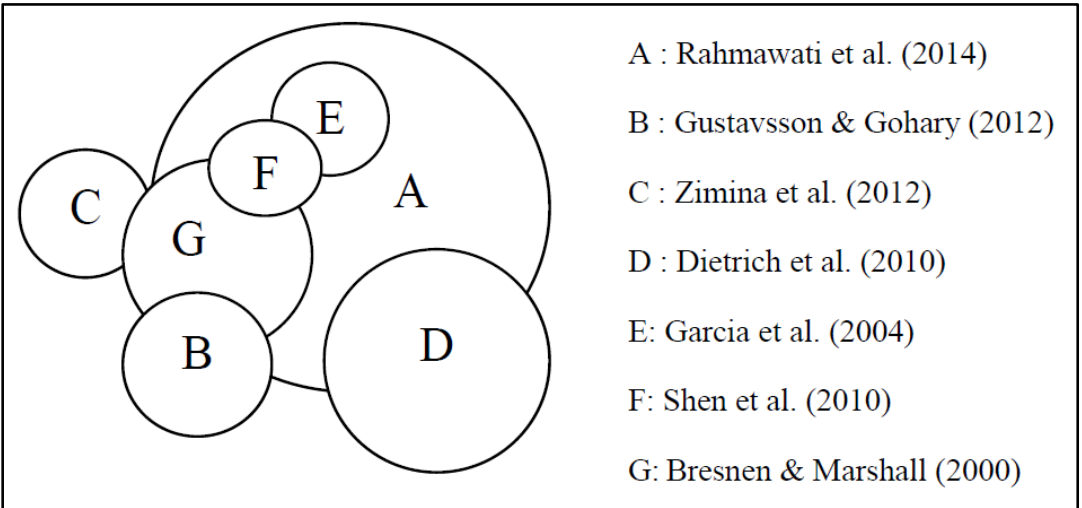

Fig. 2. Position of previous studies

\section{Research methodology}

The data collected from survey using distributed questionnaires, interview as well as observation. The researcher generally factor analyse the sample of more than 50 observations [12]. The number of variables is taken into consideration when designing the size of sample. The most popular ratio N:p (Sample to Variables, STV ratio) are 5:1 or 10:1 [13]. Staff in a Kuala Lumpur construction industry is set as the population for our research. Measurement technique used in questionnaires is Likert Scale on a five-point categorical scale $(1=$ strongly disagree; 2 = disagree; $3=$ neutral; 4 = agree; 5 $=$ strongly agree). The Likert Scale measures the respondents' perceptions by measuring the respondents' agreement to the success factors of collaborative approach in delivering sustainable construction. All the data collected is primary and will be analysed using scatter plot of mean and standard deviation analysis. It is used to identify the intensity of the agreement and consistency of agreements respectively. As presented in Fig 3., the mean and standard deviation scatter plot is needed to identify the most important factor, which in the concept all of them will gather at quadrant 4 (high mean score and low standard deviation. Factors that are gathered in quadrant 4 show that most respondents agree that the factors are important, and the most important thing is there is few different perspectives between respondents related with factors' level of importance. Factor analysis is also utilised to analyse similarities between factors to get new grouped factors.

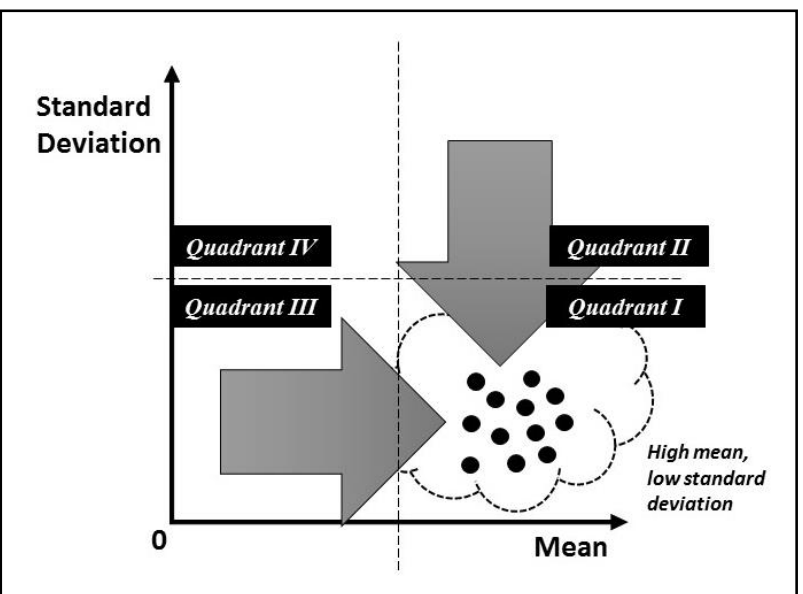

Fig. 3. Concept of mean and standard deviation analysis

\section{Result and discussion}

\subsection{Respondents' demographic profile}

A two-page self-administered questionnaire is sent out to project stakeholders in Malaysia, consisting of an introduction part explaining the purpose of the survey, a section of personal background and last section of Likert Scale rating to collaboration factors. By the end of the cutoff date, 60 returned questionnaires are received from project stakeholders in Kuala Lumpur.

The respondents comprise of project stakeholders from 4 categories of company. $52 \%$ of respondents are contractors, $32 \%$ of respondents are working in 
consultancy agency and $13 \%$ of respondents are developers. In term of job-scope, $36 \%$ of respondents are in charge in design, while the remaining major in supervision $(33 \%)$, management $(23 \%)$, procurement and purchasing $(2 \%)$ and others.

\subsection{Criticality of factors}

Based on the mean (M) and standard deviation (STD) scores, a decision can be made on the criticality of each factor. To make the collaboration profiling more holistic, all the twelve collaboration factors are ranked according to their means and standard deviation as rated in terms of their significance in delivering sustainable construction. Table 2. shows the ranking of critical success factors of collaborative approach in delivering sustainable construction in ascending sequence. The synthesis of each factor's importance with previous studies and empirical conditions is presented in Table 3 .

Coordination among project stakeholders is agreed as the most critical success collaboration factor in delivering sustainable construction. Most of the construction companies in Malaysia are managed in old system which is in hierarchical structure. In such case, coordination that manages the uni-directional tasks across multiple levels plays significance role for collaboration. The job-scopes and responsibilities of each project stakeholders of a construction project are clearly stated and formed [9]. This situation may create the boundaries between project stakeholders and gaps to the flow of different stages of a construction project. Respondents have agreed that fully integrated team is needed to remove boundaries and allow collaboration. This can be achieved by sharing project stakeholders' operational responsibilities,

As a construction project involves project stakeholders from diverse technical background and preferences, mutual support among them is crucial for collaboration. The respondents have agreed that the existence of understanding, respect and ability to compromise in mutual support ease the delivery of a sustainable construction project [14]. Innovation of construction design and method has been developing quickly all over the world. The innovation is providing more and more design alternatives. The compatible software is intelligent enough to integrate every design alternatives from different areas of a structure [11]. In such rapidly changing construction field, the use of compatible software makes collaboration easier and faster.

The respondents have agreed that the ability of turning knowledge and data into action determine the successful-ness of a sustainable construction project. Knowledge Management (KM) by using right technology and organization structure greatly affect collaboration [4]. Partnering and alliancing arrangements enable the fairness in risk and profit sharing among project stakeholders [8]. However, the business culture in Malaysia emphasizes more on individual profits instead of sharing of wealth. Therefore, the partnering and alliancing arrangement gain less agreement from respondents.

The alignment between the real intensity of effort put by each project stakeholders and the expectation on effort has been agreed by respondents that this enhances collaboration. The alignment between expectations with the realization of efforts avoids conflicts and at the same time promotes the shared goal among project stakeholders [4]. Effective communication among project stakeholders that allows updated information among project stakeholders strengthens collaboration. High frequency of communication is needed in order to ensure the effectiveness [4]. However, the high frequency of communication is time and energy consuming. The collaboration factor of effective communication between all project stakeholders therefore gains large divergence of agreement from respondents.

The collaboration factor of cohesion among project stakeholders has low intensity of agreement and moderate divergence of agreement from respondents. As the duration of a construction project becomes shorter due to advanced construction technology, the time allowed for the generation of cohesion among project stakeholders is limited as well. Therefore, the concept of cohesion among project stakeholders may become unrealistic. Virtual workspace is still in adapting stage for Malaysia construction industry. The implementation of virtual workspace is not affordable for all project stakeholders especially for sub-contractors [6]. Hence, the respondents do not agree that virtual workspace can effectively and significantly enhance collaboration among all project stakeholders.

Smaller focus group is designed to provide specific and professional technical solution [3]. Smaller focus group from all project stakeholders is difficult to be implemented in Malaysia construction industry. The lacking of competence professional from each project stakeholders to form a smaller focus group limits this factor successfulness in realising collaboration. Sharing workplace for all project stakeholders is rated to be the least significant factor in supporting collaboration. Sharing workplace facilitates communication and collaboration [9]. However, this factor is a double-edge sword in which difference of interest and preference from each project stakeholders may increase the chance of misunderstanding and conflicts as all the manpower is centralised in a sharing workplace.

Table 2. Ranking of collaboration factors

\begin{tabular}{|l|c|c|c|c|c|}
\hline \multicolumn{1}{|c|}{ Factors } & M & $\begin{array}{c}\text { M } \\
\text { Rank }\end{array}$ & STD & $\begin{array}{c}\text { STD } \\
\text { Rank }\end{array}$ & $\begin{array}{c}\text { Overall } \\
\text { Rank }\end{array}$ \\
\hline Coordination among all project stakeholders & 4.45 & 1 & 0.65 & 4 & 1 \\
\hline Sharing stakeholders' operational responsibilities & 4.10 & 6 & 0.60 & 2 & 2 \\
\hline Mutual support between project stakeholders & 4.22 & 5 & 0.64 & 3 & 3 \\
\hline
\end{tabular}




\begin{tabular}{|l|c|c|c|c|c|}
\hline \multicolumn{1}{|c|}{ Factors } & M & $\begin{array}{c}\text { M } \\
\text { Rank }\end{array}$ & STD & $\begin{array}{c}\text { STD } \\
\text { Rank }\end{array}$ & $\begin{array}{c}\text { Overall } \\
\text { Rank }\end{array}$ \\
\hline The use of compatible software & 4.42 & 2 & 0.70 & 8 & 4 \\
\hline The use of Knowledge Management (KM) & 4.32 & 4 & 0.68 & 7 & 5 \\
\hline $\begin{array}{l}\text { Partnering/ alliancing arrangements among project } \\
\text { stakeholders }\end{array}$ & 3.95 & 10 & 0.57 & 1 & 6 \\
\hline $\begin{array}{l}\text { Alignment between expectations with the realization of } \\
\text { efforts }\end{array}$ & 4.10 & 6 & 0.66 & 5 & 7 \\
\hline Effective communication between all project stakeholders & 4.33 & 3 & 0.84 & 9 & 8 \\
\hline Cohesion among project stakeholders & 4.00 & 8 & 0.66 & 6 & 9 \\
\hline Virtual workspace for all project stakeholders & 3.98 & 9 & 0.91 & 10 & 10 \\
\hline Smaller focus group from all project stakeholders & 3.78 & 11 & 0.92 & 11 & 11 \\
\hline Sharing workplace for all project stakeholders & 3.32 & 12 & 0.97 & 12 & 12 \\
\hline
\end{tabular}

Table 3. Empirical validation of collaboration factors

\begin{tabular}{|c|c|c|c|}
\hline $\begin{array}{l}\text { Ran } \\
\mathbf{k}\end{array}$ & Factors & Previous Study & Empirical \\
\hline 1 & $\begin{array}{l}\text { Coordination among all project } \\
\text { stakeholders }\end{array}$ & $\begin{array}{l}\text { Manage uni-directional tasks } \\
\text { across multiple levels [15] }\end{array}$ & $\begin{array}{l}\text { Effective in hierarchical } \\
\text { organization structure }\end{array}$ \\
\hline 2 & $\begin{array}{l}\text { Sharing stakeholders' operational } \\
\text { responsibilities }\end{array}$ & $\begin{array}{l}\text { Enhance flexibility in roles of } \\
\text { project stakeholders [9] }\end{array}$ & Breaking project stakeholders' gap \\
\hline 3 & $\begin{array}{l}\text { Mutual support between project } \\
\text { stakeholders }\end{array}$ & $\begin{array}{l}\text { Existence of understanding } \\
\text { and respect for each other } \\
{[14]}\end{array}$ & $\begin{array}{l}\text { Importance of } \\
\text { compromising to achieve } \\
\text { common goal }\end{array}$ \\
\hline 4 & The use of compatible software & $\begin{array}{l}\text { Handle rapidly changing } \\
\text { situations in economical way } \\
{[11]}\end{array}$ & Support innovation \\
\hline 5 & $\begin{array}{l}\text { The use of Knowledge } \\
\text { Management (KM) }\end{array}$ & $\begin{array}{l}\text { Ability to turn knowledge into } \\
\text { actions [4] }\end{array}$ & $\begin{array}{l}\text { Ensure right information input and } \\
\text { flow }\end{array}$ \\
\hline 6 & $\begin{array}{l}\text { Partnering/ alliancing } \\
\text { arrangements among project } \\
\text { stakeholders }\end{array}$ & $\begin{array}{l}\text { Sharing of profit and risk } \\
\text { among all project stakeholders } \\
\text { [8] }\end{array}$ & $\begin{array}{l}\text { Malaysia construction industry } \\
\text { emphasizes more on individual } \\
\text { profits }\end{array}$ \\
\hline 7 & $\begin{array}{l}\text { Alignment between expectations } \\
\text { with the realization of efforts }\end{array}$ & $\begin{array}{l}\text { Determine project } \\
\text { stakeholders' attitude and } \\
\text { behaviour [7] }\end{array}$ & $\begin{array}{l}\text { Avoid conflicts and } \\
\text { disappointment }\end{array}$ \\
\hline 8 & $\begin{array}{l}\text { Effective communication between } \\
\text { all project stakeholders }\end{array}$ & $\begin{array}{l}\text { Open sharing of ideas and } \\
\text { updated information [4] }\end{array}$ & Time and energy consuming \\
\hline 9 & $\begin{array}{l}\text { Cohesion among project } \\
\text { stakeholders }\end{array}$ & $\begin{array}{l}\text { Willingness to engage and } \\
\text { collaborate to each other [4] }\end{array}$ & Unrealistic due to time constraint \\
\hline 10 & $\begin{array}{l}\text { Virtual workspace for all project } \\
\text { stakeholders }\end{array}$ & $\begin{array}{l}\text { Solve physical boundary and } \\
\text { improve productivity }[11,7]\end{array}$ & $\begin{array}{l}\text { Implementation of BIM is not } \\
\text { common }\end{array}$ \\
\hline 11 & $\begin{array}{l}\text { Smaller focus group from all } \\
\text { project stakeholders }\end{array}$ & $\begin{array}{l}\text { Focus specifically on different } \\
\text { problems [3] }\end{array}$ & Lacking of competence profession \\
\hline 12 & $\begin{array}{l}\text { Sharing workplace for all project } \\
\text { stakeholders }\end{array}$ & $\begin{array}{l}\text { Does not limit social } \\
\text { interaction to formal events } \\
\text { only [9] }\end{array}$ & $\begin{array}{l}\text { Centralisation of manpower allows } \\
\text { more conflicts and } \\
\text { misunderstanding }\end{array}$ \\
\hline
\end{tabular}

\subsection{Grouping of Factors}

The adequacy of data for factor analysis is usually evaluated using Kaiser-Meyer-Olkin (KMO) Measure and Bartlett's test of sphericity. KMO in the $0.90 \mathrm{~s}$ indicates that the data adequacy is marvellous; in the $0.80 \mathrm{~s}$ is meritorious; in the $0.70 \mathrm{~s}$ is middling; in the $0.60 \mathrm{~s}$ is mediocre; in the $0.50 \mathrm{~s}$ is miserable and below 0.50 is 
unacceptable (Kaiser, 1974). The Bartlett's test of sphericity should be significant $(\rho<0.05)$. The rotated factor loading matrix for all twelve collaboration factors shown in Table 4.

Table 4. Rotated factor loading matrix

\begin{tabular}{|c|c|c|c|c|c|}
\hline \multirow{2}{*}{ Collaboration Factors } & \multicolumn{5}{|c|}{ Component } \\
\hline & 1 & 2 & 3 & 4 & 5 \\
\hline Coordination & 0.851 & 0.165 & $-\overline{0}-056$ & 0.033 & 0.021 \\
\hline Communication & 0.697 & 0.186 & 0.061 & 0.150 & $-\overline{0}(29$ \\
\hline Software & 0.653 & -.012 & 0.234 & $\begin{array}{l}- \\
0.025\end{array}$ & 0.500 \\
\hline Virtual Workspace & 0.567 & 0.514 & 0.138 & $\begin{array}{l}- \\
0.001\end{array}$ & 0.016 \\
\hline Aligned Effort & 0.426 & 0.744 & 0.008 & 0.159 & $\begin{array}{l}- \\
0.151\end{array}$ \\
\hline Sharing Workplace & 0.087 & 0.742 & 0.139 & 0.134 & 0.231 \\
\hline Cohesion & 0.060 & 0.452 & 0.310 & 0.412 & 0.311 \\
\hline Smaller Focus Group & $-\overline{0}-142$ & 0.219 & 0.843 & 0.077 & $-\overline{0}-012$ \\
\hline Knowledge Management & 0.391 & $\overline{0}-004$ & 0.802 & 0.096 & 0.095 \\
\hline Sharing Operational Responsibilities & - & 0.102 & 0.175 & 0.867 & $\overline{-}-066$ \\
\hline Mutual Support & 0.199 & $-\overline{0}-111$ & $\begin{array}{l}- \\
0.038\end{array}$ & 0.729 & 0.150 \\
\hline Partnering Arrangement & -0.59 & 0.124 & 0.002 & 0.103 & 0.882 \\
\hline \multicolumn{6}{|l|}{ Notes } \\
\hline \multicolumn{6}{|l|}{ Extraction Method: Principal Component Analysis } \\
\hline \multicolumn{6}{|c|}{$\begin{array}{l}\text { Rotation Method: Varimax with Kaiser Normalization. }{ }^{\text {a }} \\
\text { aRotation converged in } 9 \text { iterations. }\end{array}$} \\
\hline
\end{tabular}

In this research, the quality of data is mediocre as $\mathrm{KMO}$ is 0.627 , in Bartlett's sphericity test, $\rho<0.0001$. For factors' extraction, principal components analysis is used. In computation, Varimax rotation with Kaiser normalisation is performed.

The analysis has identified five components (1: Information Flow; 2: Common Goal; 3: Information; 4: Operational Engagement; 5: Financial Engagement) that consists eleven collaboration factors. The factor of cohesion among project stakeholders is excluded in factors clustering due to low factors loading values that are below \pm 0.5 . The five new factors are information flow (factor 1), common goal (factor 2), information (factor 3), operational engagement (factor 4), and also financial engagement (factor 5).

\subsubsection{Information Flow}

The first identified group encompasses factors to ensure effective information flow, first and foremost coordination among all project stakeholders; as well as effective communication between all project stakeholders; the use of compatible software and virtual workspace among all project stakeholders. Coordination and communication allow the information flow verbally between project stakeholders. Compatible software is a media to store and record the information [11]. Virtual workspace ensure information flow without time, physical and geographical limitations $[11,7]$.

\subsubsection{Common Goal}

The second identified group encompasses factors to ensure existence of common goal among all project stakeholders, which are alignment between expectations with the realization of efforts as well as sharing workplace for all project stakeholders. Alignment of realization of effort with expectation makes sure all project stakeholders acknowledge sustainable construction as common goal and agree to offer required contributions for the goal [4]. Sharing workplace eliminates cultural difference by instilling the same interest through increasing socialization [3].

Malaysian Construction Industry has been urged to shift from traditional practice to sustainable construction [16]. Sustainability-oriented concept in construction project shall occurs from top-management to every staff [17]. The second group of collaboration factors (Common Goal) functions to implement sustainable construction as common goal among all project stakeholders. Eventually, by having same common objective, the two factors organize and engineer the organizational structure and process for facilitating the implementation of sustainable policy and strategy. 


\subsubsection{Information}

The third identified group encompasses factors to ensure sufficient information for improving technical availability and capability, which are smaller focus groups from all project stakeholders and the use of Knowledge Management. Smaller focus group with satisfying competency and experience is an information provider [3]. Knowledge Management integrates data and knowledge as useful information for sustainable construction [7].

Classically, innovation with the purpose of promoting sustainable energy often involves two main strategies: energy efficiency and renewable energy [18]. Technical capacity; physical and knowledge resources as well as information management strategies play crucial role in achieving the innovation in design, procurement and construction process of a sustainable construction project. The first group of collaboration factors (Information Flow) and third group of collaboration factors (Information) enhance the company's capacity of technology and innovation for increasing the sustainability of construction process, promoting green design and best practice construction procurement throughout the supply chain.

\subsubsection{Operational Engagement}

The fourth identified group encompasses factors to ensure operational engagement between project stakeholders, which are sharing stakeholders' operational responsibilities and mutual support between project stakeholders. Sharing of operational responsibilities and mutual support enhance flexibility in roles and unforeseen circumstances $[3,4]$. As such, these two collaboration factors ensure all the project stakeholders are engaged in operational level.

Organizations are increasingly aware that choices made about products and processes can have profound environmental and social implications [17]. Sharing of operational responsibilities and mutual support indirectly shape the organizational structure and process towards effective sustainability concept implementation in construction. The fourth group of collaboration factors (Operational Engagement) allows sharing of technical availability and knowledge, information as well as breaking regulatory constraints in operational level. Strong operational engagement among stakeholders in a project also improves business competiveness.

\subsubsection{Financial Engagement}

The last identified component includes one factor only, which is partnering/ alliancing arrangements among project stakeholders that ensure financial engagement between project stakeholders. Partnering or alliancing arrangement emphasizes the pain-gain mechanism that allows sharing of profit and risk among all project stakeholders [8]. This has developed the engagement between project stakeholders into financial level.
The decision of sustainability option for in industry is based on sound business criteria rather than benefits of sustainable construction [19]. The strategies for sustainable construction are to be more profitable and more competitive as well as respecting and treating all stakeholders more fairly. The fifth group of collaboration factors (Financial Engagement) complies with different governmental sustainability legislations, including environmental requirement and social responsibility, to improve business competitiveness.

\section{Conclusion}

This research examines the success factors of collaborative approach in supporting decision making to deliver sustainable construction. Twelve collaboration supporting factors have been identified from previous studies using literature review. Among all the identified factors, mean and standard deviation analysis identified that coordination among all project stakeholders as the most critical factor. Factor analysis indicates that collaboration factors can be grouped into five groups: information; information flow; common goal among project stakeholders; operational engagement between project stakeholders as well as financial engagement between project stakeholders.

This research has several important academic contributions. First, the area of collaboration factors in delivering sustainable construction is with scant number of research conducted, despite its importance. Majority of research studies in the contemporary literature are conducted in the western countries. This research therefore helps to enrich the existing literature in the field and contributes to devise a comprehensive and rigorous collaboration factors in delivering sustainable construction.

There are also several managerial implications in this research. It is confirmed, firstly, that collaborative approach is needed in delivering sustainable construction. Collaborative approach is able to engage multidisciplinary stakeholders not only operationally and financially but also in having a mind-set of sustainable construction to be the common objective. Collaborative approach also manages information efficiently and effectively to improve innovation and technology in sustainable design and construction of a project. As such, industry players shall be ready and aware to adopt all the success factors of collaborative approach to their own organization structure.

Authors appreciate the recognition and awards in forms of research grant (STIRF - Short Term Internal Research Funding) and fellowship from Universiti Teknologi PETRONAS.

\section{References}

1. X. Li, Y. Zhu, and Z. Zhang, An LCA-based environmental impact assessment model for construction processes, Building and Environment, vol. 45, pp. 766-775 (2010) 
2. W. L. Bedwell, J. L. Wildman, D. DiazGranados, M. Salazar, W. S. Kramer, and E. Salas, Collaboration at work: An integrative multilevel conceptualization, Human Resource Management Review, vol. 22, pp. 128-145 (2012)

3. T. K. Gustavsson and H. Gohary, Boundary action in construction projects: new collaborative project practices, International Journal of Managing, vol. 5 (2012)

4. P. Dietrich, P. Eskerod, D. Dalcher, and B. Sandhawalia, The dynamics of collaboration in multipartner projects, Project Management Journal, vol. 41, pp. 59-78 (2010)

5. Y. Rahmawati, C. Utomo, N. Anwar, C. B. Nurcahyo, and N. P. Negoro, Theoretical Framework of Collaborative Design Issues, Jurnal Teknologi, vol. 70 (2014)

6. D. Migilinskas, V. Popov, V. Juocevicius, and L. Ustinovichius, The Benefits, Obstacles and Problems of Practical Bim Implementation, Procedia Engineering, vol. 57, pp. 767-774 (2013)

7. Y. Rahmawati, C. Utomo, N. Anwar, P. Setijanti, and C. B. Nurcahyo, An Empirical Model for Successful Collaborative Design Towards Sustainable Project Development, Journal of Sustainable Development, vol. 7 (2014)

8. D. Zimina, G. Ballard, and C. Pasquire, Target value design: using collaboration and a lean approach to reduce construction cost, Construction Management and Economics, vol. 30, pp. 383-398 (2012)

9. M. Bresnen and N. Marshall, Building partnerships: Case studies of client contractor collaboration in the UK construction industry, Construction Management and Economics, vol. 18, pp. 819-832 (2000)

10. Garcia, A. C. B., Kunz, J., Ekstrom, M., \& Kiviniemi, A., Building a project ontology with extreme collaboration and virtual design and construction, Advanced Engineering Informatics, 18, 71-83 (2004)

11. W. Shen, Q. Hao, H. Mak, J. Neelamkavil, H. Xie, J. Dickinson, et al., Systems integration and collaboration in architecture, engineering, construction, and facilities management: A review, Advanced Engineering Informatics vol. 24, pp. 196207 (2010)

12. J. F. Hair, W. C. Black, B. J. Babin, and R. E. Anderson, Multivariate Data Analysis, vol. 7th Edition (2009)

13. A. B. Costello and J. W. Osborne, Best Practices in Exploratory Factor Analysis: Four Recommendations for Getting the Most From Your Analysis, Practical Assessment, Research \& Evaluation, vol. 10 (2005)

14. P. W. Mattessich and B. R. Monsey, Collaboration: What Makes It Work. A Review of Research Literature on Factors Influencing Successful Collaboration. St. Paul, Minnesota: Amherst H. Wilder Foundation (1992)

15. S. C. Y. Lu, W. Elmaraghy, G. Schuh, and R. Wilhelm, A Scientific Foundation of Collaborative
Engineering, CIRP Annals, vol. 56, pp. 605-634 (2007)

16. K. A. M. Kamar, Z. A. Hamid, M. K. Ghani, C. Egbu, and M. Arif, Collaboration Initiative on Green Construction and Sustainability through Industrialized Buildings Systems (IBS) in the Malaysian Construction Industry, International Journal of Sustainable Construction Engineering \& Technology (2010)

17. A. Presley and L. Meade, Benchmarking for sustainability: an application to the sustainable construction industry, Benchmarking: An International Journal, vol. 17, pp. 435-451 (2010)

18. S. M. Badi and S. D. Pryke, Assessing the quality of collaboration towards the achievement of Sustainable Energy Innovation in PFI school projects, International Journal of Managing Projects in Business, vol. 8 (2015)

19. M. Pitt, M. Tucker, M. Riley, and J. Longden, Towards sustainable construction: promotion and practices, Construction Innovation, vol. 9, pp. 201224 (2009)

20. L. R. Fabrigar and D. T. Wegener, Exploratory Factor Analysis (Understanding Statistics). New York: Oxford University Press (2011) 